\title{
O segmento de distribuição de energia elétrica no Brasil: uma avaliação das crises hídricas enfrentadas em 2001 e 2021
}

\section{The Brazil's power distribution utililites: an assessment about hydro crisis in 2001 and 2021}

\author{
Marcos de Abreu Soares ${ }^{1}$, Hirdan Katarina de Medeiros Costa ${ }^{1}$
}

\begin{abstract}
RESUMO
O presente artigo pretende identificar as estratégias utilizadas pelo governo federal brasileiro para mitigar os impactos das crises hídricas do setor elétrico, em especial, no segmento distribuição de energia elétrica ocorridas no Brasil, em 2001 e 2021. Além disso, procura mapear oportunidades para aprimoramento da regulamentação. A metodologia consiste em análise qualitativa, exploratória e descritiva, baseada na revisão da legislação em vigor no país, regulamentações da ANEEL, trabalhos científicos e artigos técnicos sobre o setor de energia elétrica no Brasil. Como resultados, aponta-se que o Sistema Elétrico Brasileiro é baseado em um modelo de produção de energia a partir da hidroeletricidade, dessa forma, os impactos ambientais associados às mudanças climáticas no mundo e as decisões de políticas do estado Brasileiro como o abandono da construção de novas usinas hidrelétricas com reservatório de acumulação, no futuro poderão permitir o surgimento de novas crises no fornecimento de energia elétrica e/ou no atendimento da demanda de pico do sistema, assim sendo, há uma oportunidade regulatória de aprimorar as regras vigentes, de modo a preparar o Brasil para futuras crises setorias, já que nos últimos vinte anos tivemos pelo menos cinco, bem como garantir o fornecimento de energia com um menor custo.
\end{abstract}

Palavras-chave: Setor elétrico brasileiro; Segmento de distribuição de energia; Crises de 2001 e 2021; Regulamentação e hidroeletrecidade

\begin{abstract}
This article intends to identify the strategies the Brazilian Federal Government used to mitigate the impacts of the 2001 and 2021 water crisis in the power sector, considering specially the distribution utilities. Besides that, it seeks to map opportunities to improve the regulation. The methodology consisted of qualitative, exploratory and descriptive analysis, based on legislation revision, ANEEL's regulations, scientific and technical articles on the Brazilian power sector. Results show the Brazilian Power System is supported by hydroelectricity, in such a way that the environmental impacts associated to climate change worldwide and the policy decision-making in Brazil, being an example the renouncement of the construction of hydro powerplants with reservoirs, might in the future allow the appearance of new crisis in the power supply and/or in the meeting of peak demand. Given this scenario, there is a regulatory opportunity to improve the regulation and prepare Brazil for future sectorial crisis, considering that in the last twenty years Brazil hat at least five of them, as well as to secure the power supply at the lowest cost possible.
\end{abstract}

Keywords: Brazilian power sector; Power Distribution Utilities; 2001 and 2021 crisis; Regulation and hydropower.

\footnotetext{
${ }^{1}$ Universidade de São Paulo.

*E-mail: marcos.soares@edp.com
} 


\section{INTRODUÇÃO}

O modelo do Setor Elétrico Brasileiro é predominante hídrico, quando, comparados os dados das crises de 2001 e 2021, constata-se uma redução relevante na matriz de geração de energia. Segundo (PSR, 2021), a matriz atual do país possui $65 \%$ hidroelétricas, $20 \%$ térmicas e $15 \%$ demais fontes, principalmente eólica e solar, enquanto, em 2001 era 90\% hidroelétrico e 10\% térmico. Conforme (Tolmasquim,2015) o aproveitamento dos recursos hídricos é fundamental para a produção de energia elétrica no país, de forma, que historicamente grandes usinas com reservatório de acumulação foram construídas no século passado, em especial, na região sudeste do país, também, aproveitando a topografia favorável de quedas d'água.

Inicialmente, a produção de energia a partir de fonte hídrica é uma importante contribuição na manutenção da matriz de energia renovável, tanto, em relação a uma menor emissão de gases do efeito estufa, como, nos custos de produção de energia que posteriormente serão pagos pelos consumidores, por meio, da fatura de energia sob responsabilidade das Distribuidoras locais (PSR, 2020).

Contudo, a forte dependência da geração hídrica expõe o país às mudanças climáticas que afetam o regime de chuvas nas principais bacias da região sudeste, que, concentram $70 \%$ dos reservatórios do Brasil. Além disso, nos tempos atuais, ocorre um impasse sob o múltiplo uso de água nas principais Bacias, já que, existe a necessidade de manutenção de uma vazão mínima por parte das Usinas, de forma, a permitir o consumo humano, produção agrícola, transporte fluvial, entre outros (PSR, 2021).

Quando, comparam-se as crises de 2001 e 2021, observa-se que ambas tratam de problemas na compatibilização da oferta e demanda de energia, onde, a primeira, culminou em um racionamento (Kelman, 2001). No entanto, a segunda teve o risco de racionamento mitigado em 2021, mediante a implementação de medidas com elevado impacto tarifário no próximo anos aos consumidores (Kelman, 2001).

Assim sendo, propõe-se no presente artigo uma análise das medidas adotadas pelo Governo Federal nas duas crises do setor elétrico, bem como, o eventual impacto na sociedade, em especial, a possibilidade de elevados aumentos tarifários no contexto social e econômico do país e do mundo, durante a pandemia COVID 19. Por fim, propõe-se 
algumas reflexões no contexto regulatório sobre eventuais medidas a serem avaliadas em futuras crises.

O artigo é composto por 5 seções, além desta Introdução. A Seção 2 explica o papel do segmento de distribuição de energia para o setor elétrico. A Seção 3 analisa a crise do setor elétrico de 2001, contemplando as principais medidas adotadas. Em seguida, na Seção 4, são avaliadas as medidas tomadas na crise de 2021. na Seção 5, uma breve avaliação sobre o impacto tarifário para os consumidores, em especial, nas tarifas de energia nas duas crises. Na Seção 6, finalmente, as conclusões são apresentadas e comentadas.

\section{O PAPEL DO SEgMENTO DE DISTRIBUIÇÃO DE ENERGIA NO SETOR ELÉTRICO BRASILEIRO}

Para (Caldas, 2011), a concessão de serviços públicos no Brasil acompanhou as dificuldades do Estado na definição do seu papel, ora como mero observador da atuação da iniciativa privada, investidor relevante e regulador, ora tomando decisões políticas e interferindo na segurança jurídica e regulatória do setor. No início do século passado, a iniciativa privada atuou no desenvolvimento do setor elétrico a partir da desordem regulatória promovida pelo Estado brasileiro em todos os seus entes da Federação. Na segunda metade do século, houve a necessidade de o Estado assumir um papel preponderante na realização dos investimentos nos segmentos de geração, transmissão e distribuição, contudo as crises econômicas e a escassez de recursos obrigaram a redefinição do seu papel por meio de uma política de concessão de serviços públicos para a iniciativa privada, momento que vivemos até os dias atuais.

Conforme (Acende Brasil, 2011), a Lei das Concessões nº 8.987/95 decorre do artigo $n^{\circ} 175$ da Constituição Federal, sendo que os principais dispositivos da referida lei tratam de conceituar os temas relativos a poder concedente, concessão de obra pública, concessão de serviço público e permissão de serviço público. Além disso, são tratados outros temas afetos à qualidade dos serviços, como a continuidade, regularidade, segurança, eficiência e cortesia.

Outro aspecto relevante da lei trata do equilíbrio econômico e financeiro através de uma política tarifária, onde são previstos os reajustes anuais e as revisões tarifárias, e também são consideradas as receitas decorrentes de outras fontes da concessão. Por fim, 
são abordados os direitos e as obrigações do concessionário, inclusive nos assuntos de terceirização dos serviços e na eventual transferência do controle societário da concessão.

Segundo (Caldas, 2011), a concessão remete a administração de um bem público ou serviço público por um particular, mediante uma remuneração, através da transferência pelo Estado, a partir da assinatura de um contrato de concessão, dos riscos na gestão do negócio, bem como das garantias do equilíbrio econômico-financeiro dos investimentos realizados por meio da cobrança de tarifas. No entanto, a exceção nasce no segmento de geração de energia, cuja atividade pode ser explorada por meio de uma concessão de serviço público, produção independente ou autoprodução.

De acordo com (Christofari, 2015), o segmento de distribuição de energia elétrica é responsável por garantir o fluxo de toda cadeia do Setor Elétrico Brasileiro, pois sua saúde econômica e financeira permite o fluxo de pagamentos aos geradores, transmissores, e o poder público por meio de impostos, tributos e encargos setoriais. $\mathrm{O}$ melhor modelo regulatório é aquele que preserva o interesse do consumidor em receber serviços adequados, bem como garante a rentabilidade dos investidores e estimula a eficiência de custos para toda cadeia produtiva do setor elétrico (Geração, Transmissão e Distribuição). Conforme (Christofari, 2015), nesse sentido, existem três modelos regulatórios que se destacam: i) taxa de retorno ou custo do serviço; ii) revenue cap; e iii) price cap. O modelo regulatório price cap é o adotado para o segmento de distribuição no Brasil.

No modelo regulatório price cap, a Receita Total é obtida de forma indireta, a partir do cálculo do Mercado Faturado versus Tarifa Teto. Portanto, não há garantia de Receita para os agentes de distribuição, no qual a variação da receita a partir da variação do consumo dos clientes impacta a Distribuidora, o qual denomina-se "Risco de Mercado". Adicionalmente, as Empresas são obrigadas a adquirir energia com base em previsões futuras de até 5 anos de expectativa de consumo. Nesse sentido, a realização de um consumo menor que o previsto poderá provocar oferta excedente de contratos de energia adquiridos em leilões públicos promovidos pela ANEEL, porém, sem a respectiva contrapartida de faturamento por parte dos consumidores, gerando portanto o " Risco de Sobrecontratação"(PIRES, 1998).

Portanto, no modelo de price cap adotado no Brasil e abrangido nos contratos de Concessão, é estabelecido uma clara atribuição de responsabilidade às Distribuidoras na 
gestão dos riscos de mercado, sobrecontratação ou subcontratação de energia e inadimplência (Acende Brasil, 2011).

\section{A CRISE DE FORNECIMENTO EM 2001}

Conforme (Tolmasquim, 2015), em 2001, o Brasil atravessou uma crise de suprimento de energia elétrica que levou a um racionamento, que previu o corte de $20 \%$ a 25\% no consumo de energia elétrica nas regiões Sudeste-Centro Oeste e Nordeste. Além disso, em 2001, o Produto Interno Bruto (PIB) foi de 1,3\%, inferior ao crescimento de $4,36 \%$ em 2000, dessa forma, os reflexos econômicos e sociais foram percebidos ao longo daquela década.

\subsection{Contexto Histórico}

Segundo (De Araújo,2001), na década de 1980, o aumento do acesso à eletricidade no país resultou em uma demanda elétrica crescente. Ao mesmo tempo, o país enfrentava uma grave crise econômica e as empresas estatais não tinham recursos para investir em novos ativos de geração e transmissão de energia elétrica. Isto culminou em um estado de escassez crônica no suprimento de eletricidade no Brasil, verificado pela recorrência de apagões.

Ainda, (De Araújo,2001) afirma que, durante a década de 1990, o governo brasileiro, para solucionar a problemática da falta de investimentos, propôs uma reforma no sistema elétrico do país, a qual ficou conhecida como a Reestruturação do Setor Elétrico Brasileiro (RE-SEB). Tal modelo, tinha como principais características a desverticalização das empresas estatais; a privatização dos setores de geração, transmissão e distribuição e a introdução da competição na geração e comercialização.

No governo de Fernando Henrique Cardoso, que promulgou a Lei no 9.074/95, que trata da reforma do setor elétrico, instituiu a desverticalização do setor, e também o livre acesso aos sistemas de transmissão e distribuição, , assim como criou agentes como consumidores livres, entre outros. Instituiu a ANEEL por meio da Lei no 9.427/96, o Operador Nacional do Sistema - ONS e o Mercado Atacadista de Energia - MAE, por meio da Lei no 9.648/98. 
No entanto, segundo (Sauer, Vieira e Kirchner, 2001), entre 1991 e 2000, observou-se uma tendência contínua do crescimento do consumo de eletricidade $(4,1 \%$ ao ano) a taxas maiores do que as do aumento da capacidade instalada (3,3\% anuais). Nesse contexto, a partir de 1994, os reservatórios das usinas hidrelétricas brasileiras passaram a ter seus estoques continuamente reduzidos, o que significou uma diminuição progressiva da confiabilidade do sistema de geração elétrica brasileiro. Tal cenário aliado ao subinvestimento na expansão da geração (BARDELIN, 2004) culminou com o racionamento de energia em 2001.

Em 2003, foi elaborada uma nova proposta de modelo para o Sistema Elétrico Brasileiro (SEB), sumarizada no documento "Modelo Institucional do Setor Elétrico". Algumas características desta nova perspectiva foram a utilização de leilões de licitação de energia, a atualização dos cálculos da energia assegurada de geração e a obrigatoriedade de contratação para cobertura total, conforme, (Sauer, Vieira e Kirchner, 2001).

O sistema elétrico brasileiro foi organizado a partir da complementaridade hidrotérmica, no qual uma decisão individual de despacho pode não representar à melhor decisão do ponto de vista setorial. Dessa forma, para que os riscos hidrológicos das Usina hidrelétricas fossem compartilhados, uma vez que a decisão sobre o despacho centralizado é o papel do ONS, foi criado, por meio do Decreto ${ }^{\circ} 2.655$, de 2 de julho de 1998, o Mecanismo de Realocação de Energia - MRE.

O modelo atual, iniciado em 2004, e descrito acima, desempenhou bem o seu papel na expansão da geração durante um certo período, visto que permitiu que os geradores obtivessem contratos de longo prazo e com grau de risco menor.

\subsection{Principais Causas do Racionamento}

Segundo (Kelman, 2001), o Sistema Elétrico Brasileiro foi projetado para suportar cinco anos nos períodos de seca, pois, os reservatórios de regularização das Usinas Hidrelétricas funcionam como uma poupança, no entanto, no final de 1998 o nível dos reservatórios da região sudeste/centro-oeste era 45\%, no entanto, em dezembro de 2019, os mesmos reservatórios tinha o nível de $18 \%$, ou seja, um nível crítico para o Sistema elétrico do País, já que, estes reservatórios representam $70 \%$ da reserva do Nacional. Ao 
longo do ano 2000, houve uma melhora no nível de armazenamento aumentado para 28\%, porém, sem representar um alivio na condição de criticidade do Sistema.

Nesse período, existia a obrigação regulatória por parte das Distribuidoras referente à contratação de $85 \%$ da energia para atendimento do mercado consumidor, sob pena de comprar o restante da energia no mercado de curto prazo, que possuía oscilações bruscas. Importante, que para a proteção do caixa as Distribuidoras normalmente tinham energia para atendimento de $100 \%$ do mercado de consumo, (Kelman, 2001).

De acordo (Tolmasquim, 2015) até 1998, a expansão do setor elétrico era planejada centralizadamente, respeitando a oferta e demanda do mercado. No entanto, a partir de 1998, o Novo Modelo do Setor Elétrico previu a formalização de contratos bilaterais no ambiente regulado ou livre, de forma, que a demanda projetada pelas Distribuidoras seria a base para determinar a expansão do Sistema de Geração de Energia. Com a mudança do modelo do setor elétrico a obrigação de garantir a expansão do sistema contemplando a oferta de energia nova suficiente para atender a totalidade carga passou a ser das Distribuidoras, e não mais dos geradores, contudo, a diretriz de risco de déficit do sistema foi mantida em um de $5 \%$.

Ainda conforme (Kelman, 2001), analisando as principais causas do racionamento de 2001, observa-se que em relação ao consumo ocorreu uma pequena variação inferior a $1 \%$ entre o previsto e o realizado, contudo, não contribuiu significativamente para o corte da carga. Por outro lado, os atrasos nas obras de geração e transmissão inauguradas entre 1998 e 2001, represaram uma oferta de energia ao Sistema de 22 mil GWh, que representava $15 \%$ da capacidade total de armazenamento da região sudeste, centro oeste e nordeste, juntas.

Além disso, a não construção de geração adicional prevista no Plano Decenal 1998-2007, na ordem 40 mil GWh, que representaria o aumento da capacidade de armazenamento em maio de 2001 , caiu de $32 \%$ para $58 \%$. Por fim, merece destaque o atraso na construção do terceiro circuito de Itaipu, que permitiria a importação de energia da argentina e que o vertimento de itaipu pudesse ser transformado em energia para a região sudeste, conforme (Kelman, 2001).

Outros aspectos foram considerados relevantes no agravamento da crise de 2001, como, o aumento da inadimplência na CCEE, a constatação que as garantias físicas das usinas hidrelétricas estavam superestimadass, de forma, que impedia a contratação de 
energia nova para o Sistema o que assegura confiabilidade no fornecimento (Tolmasquim, 2015).

\subsection{Principais Medidas adotadas pelo Governo}

Com o objetivo de coordenar a atuação do Governo Federal na Crise de 2001 foi constituída à Câmara de Gestão da Crise Energética (GCE), contemplando diversos órgãos do Governo Federal, já que, o decreto estabelecia o racionamento de energia nas regiões Sudeste e Centro-Oeste, Norte e Nordeste do País, conforme (Tolamasquim, 2015).

As principais medidas adotadas foram as seguintes: i) Contratação de geração emergencial de usinas térmicas montadas em barcaças, que seriam conectadas a rede das distribuidoras; ii) O programa prioritário de termoelétricas, que buscava a antecipação da operação antes de 2003, considerado a melhor solução para a crise até então; iii) Leilão de Capacidade para a contratação de 2.500 MW. Contudo, nenhuma medida foi efetivamente implementada pelo Governo (Kelman, 2001).

Adicionalmente, o Governo adotou uma estratégia para mitigar os efeitos da crise com as seguintes diretrizes: i) interconexão com argentina e Paraguai; ii) Redução do consumo nas regiões Sudeste e Nordeste; iii) Cortes programados em dias da semana; e iv) Incentivos à autogeração e cogeração (Tolmasquim, 2015).

\section{A CRISE DE FORNECIMENTO EM 2021}

O Setor Elétrico Brasileiro atravessou em 2021 um período de hidrologia desfavorável, além de que, os reflexos sociais e econômicos da Pandemia COVID 19, ainda, não foram totalmente superados pela Sociedade e pelo setor elétrico, de forma, que no momento da recuperação econômica, o pais depara-se com o risco de incapacidade de atender a demanda de energia na ponta ou a necessidade de corte da carga.

4.1 Causas do deplecionamento dos reservatórios

Conforme (PSR, 2021), as Usinas Hidrelétricas representam 64\% da capacidade de geração nacional, de forma, a garantir a segurança do sistema para o atendimento da 
demanda. A água que alimenta os rios em parte é utilizada imediatamente para a produção de energia ou guardada no reservatório da Usina para os períodos de seca.

O nível de deplecionamento dos reservatórios no Brasil sofreu uma expressiva redução por dois motivos: i) hidrologias baixas nos últimos anos; ii) utilização da água para usos diversos. Conforme (Acende Brasil, 2021), o primeiro tópico, que trata da Energia Natural Afluente (ENA) em 2021 transitou entre as 25\% piores do histórico dos últimos 90 anos, inclusive, com um resultado menor que no racionamento de 2001, dessa forma, contribui diretamente no potencial risco de racionamento em 2021.

Para o segundo tópico, o uso múltiplo da água do rio há necessidade que as Usinas liberem uma vasão mínima para o leito do rio, de forma, evitar impactos ambientais, captações de água para os municípios, projetos de irrigação, navegação, recreação e transporte fluvial, Conforme, (PSR,2020).

A principal questão deste tema é a obrigatoriedade das usinas liberaram uma quantidade de água superior a vasão natural do rio, ou seja, esta ação implica no esvaziamento do reservatório de acumulação, claro, que ocorre a geração de energia da água liderada no rio. Como exemplo o caso da Usina de Jupiá no rio paraná que é obrigada a liberar 4.000 metros cúbicos de água, enquanto, a vazão natural do rio é de 1.650 metros cúbicos, dessa forma, o reservatório sofre um processo de esvaziamento constante, ainda segundo, (PSR, 2021).

\subsection{Medidas adotadas e consequências}

De acordo, (Acende Brasil,2021) a criação da Câmara de Regras Excepcionais para Gestão Hidroenergética (CREG) foi a primeira media tomada pelo Governo com o objetivo de gerir a crise hídrica, além disso, o aumento da geração térmica, importação de energia do Uruguai e Argentina, contratação excepcional de usinas térmicas, medidas de redução do consumo (Conscientização e programa de resposta a demanda) e medidas para gestão do uso múltiplo da água em conjunto com à Agência Nacional de Águas (ANA).

Segundo (PSR, 2021) sob o ponto de vista conceitual as medidas adotadas pelo governo abarcaram três conceitos relevantes: i) Medidas pelo lado da oferta, ii) Medidas pelo lado da demanda, iii) Medidas de Comunicação. Relevante, que está última que trata das medidas de comunicação sofreu diversas críticas, pois, não demonstrou a situação dos 
reservatórios, bem como, não esclareceu as informações no programa de bonificação dos consumidores de baixa tensão, que foram estimulados a reduzir o consumo de energia entre $10 \%$ e $20 \%$, durante, os meses de setembro até dezembro de 2021 , quando comparados ao mesmo período do ano de 2020, mediante bonificação na conta de energia a cada $100 \mathrm{kWh}$.

Outra medida de destaque foi a criação da Bandeira tarifária de Escassez Hídrica, no período de agosto de 2021 até abril de 2022, com o objetivo de reduzir o déficit de caixa das distribuidoras acumulado desde o final de 2020, estimado em R $\$ 15$ bilhões de reais, bem como, cobrir os custos adicionais das medidas, em especial, o despacho de térmicas fora da ordem de mérito e a importação de energia dos países do Mercosul.

A única medida parcialmente implementada foi a Redução Voluntária de Demanda de Energia Elétrica (RVD), que estabelecia o pagamento de compensação financeira às empresas participantes do Mercado Livre de Energia que se disponham a reduzir o consumo entre setembro e dezembro de 2021. A empresa deve inicialmente se habilitar junto ao Operador Nacional do Sistema (ONS) e ofertar uma redução de consumo de no mínimo de $5 \mathrm{MW}$ (megawatt) por um período de 4 ou 7 horas consecutivas dentro da grade horária definida pelo ONS.

O Programa de Redução Voluntária da Demanda é voltado apenas a grandes consumidores que façam parte do Mercado Livre de Energia, que devem estar adimplentes com as obrigações junto à Câmara de Comercialização de Energia Elétrica (CCEE).Contudo, no início de novembro o Operadora Nacional do Sistema (NOS) anunciou o encerramento antecipado do programa, tendo em vista, a breve recuperação do nível de alguns reservatórios, onde, somente, nos meses de setembro, outubro e novembro, ocorreram operações nos montantes de 442 MW, 720 MW e 454 MW, respetivamente (Canal Energia, 2021).

\section{IMPACTOS TARIFÁRIOS PARA OS CONSUMIDORES}

De acordo com (PSR, 2021), a maior diferença entre a crise de 2001 e 2021, encontra-se no mercado de consumo de energia, pois, em 2001, praticamente todo o consumo era regulado, enquanto, hoje, cerca $30 \%$ do mercado está no ambiente livre, onde as negociações serão bilaterais entre comprador e vendedor. 
Naquele momento, havia a figura dos contratos iniciais sob a responsabilidade do Governo, mas, firmados entre os geradores e as Distribuidoras. As cláusulas destes documentos provocaram enorme divergência entre os agentes, de forma, que o Governo interveio e realizou a mediação. Então, realizou-se o acordo geral do setor que aumentou as tarifas dos consumidores há época.

Relevante, que o aumento tarifário do início do século foi realizado em um contexto de tarifas baixas em termos internacionais e a maioria dos consumidores não tinham oportunidade de migração para o ambiente livre, ainda segundo (PSR, 2021).

Vale destacar uma medida tomada pelo Governo em 2002 com o chamado segura apagão que previa a contratação de 48 térmicas, durante três anos, a fim de garantir a segurança do sistema, contudo, os consumidores arcaram com cerca de R \$ 6,5 bilhões na fatura de energia, conforme (Revista USP, 2015).

Na crise de 2021, a situação é completamente diferente em relação ao custo da energia, pois, o Brasil apresenta uma das tarifas mais caras do mundo e os consumidores dispõe de alternativas ao mercado regulado, seja, pela migração para o ambiente livre ou adoção da geração distribuída, por exemplo, ainda segundo, (PSR, 2021).

Outro aspecto importante, é a grande quantidade de agentes envolvidos, pois, atualmente existem inúmeras associações setoriais, geradores, distribuidoras, transmissoras, governo federal, prefeituras etc. Dessa forma, uma construção setorial para uma solução torna-se mais difícil e aumenta o risco de judicialização do setor elétrico, como foi visto no tema da indenização das transmissoras e GSF.

Segundo (Canal Energia, 2021), o impacto da crise hídrica no caixa das distribuidoras poderá gerar a necessidade de empréstimo setorial da ordem $R \$ 15$ bilhões de reais no início de 2022, assim sendo, o impacto na tarifa dos consumidores foi estimado em $4,45 \%$ nos processos tarifários em 2022 e 2023.Por fim, os custos com o pagamento de encargos e bandeira tarifária foram estimados em R \$ 30 bilhões em 2021 e os contratos para as térmicas do leilão de reserva a serem pagos entre 2022 e 2025 somam mais R $\$ 39$ bilhões de reais.

\section{CONCLUSÕES}

O sistema elétrico nacional está passando por um período de intensas transformações relacionadas ao tipo de fonte de oferta de eletricidade, de um cenário 
predominantemente hidráulico para uma oferta advinda de fontes renováveis, não despacháveis. No entanto, as referidas fontes não despacháveis, tais como solar e eólica, não são suficientes para suprir o período de carga máxima do sistema, o que impõe a necessidade de revisitar a decisão política de não construir Usinas Hidrelétricas com reservatório de regularização na Região Norte do Brasil, já que, provavelmente, existiriam enormes impactos ambientais e sociais.

Em contrapartida a esta decisão o Brasil está caminhando para a construção de usinas térmicas a combustível ou gás natural, que de alguma foram contribuem na emissão de gases do efeito estufa, bem como, no aumento das tarifas dos consumidores. Depreende-se que a decisão pela construção de usinas com reservatório ou a expansão das térmicas é fundamental em termos ambientais e tarifários para os consumidores do País, e representa uma decisão de política estratégica que contribui na solução de futuras crises do setor elétrico.

Segundo (PSR, 2021), ainda existe um risco de racionamento em 2022 entre 2,1\% e $8,8 \%$, dessa forma, quando se analisa as medidas adotadas pelo Governo percebe-se que foi fundamental a criação da (CREG) para a gestão única da crise hídrica, assim como, no racionamento de 2001 a criação da (GCE).

Ocorreu um aprimoramento do Governo na adoção de medidas, tanto, do lado da oferta como da demanda, uma vez que, na crise de 2001 poucas medidas foram implementadas do lado da oferta de energia, tendo em vista, os atrasos nas obras de geração e transmissão.

Em 2021, houve um aprendizado com a crise de 2001, dessa forma, praticamente todas as medidas da oferta foram implementadas, como exemplo: i) Leilões emergências para contratação de usinas disponíveis, ii) flexibilização do limite de transferência de carga entre regiões, principalmente, do norte e nordeste para o sudeste,iii) Flexibilizações de restrições de uso múltiplo da água, iv) assegurar a disponibilização de equipamentos de geração termoelétricos.

Contudo, no lado da demanda a ação de implementação do programa de resposta a demanda foi parcialmente concluída, já que, no mês de dezembro foi suspensa pelo (ONS), pois, já havia uma leve recuperação dos reservatórios, em especial, na região sudeste. Esta ação sofreu enormes críticas da iniciativa privada e das associações setoriais, pois, algumas empresas realizaram uma organização para atender a demanda do 
Governo, mas, tiveram que interromper sem uma comunicação prévia, o que futuramente poderá reduzir atração junto as indústrias.

Outra ação finalizada foi a implementação da Bandeira tarifária de escassez hídrica que onerou as tarifas dos consumidores em R $\$ 14,20$ a cada $100 \mathrm{kWh}$ consumidos. $\mathrm{O}$ aumento das bandeiras tem como objetivo sinalizar aos consumidores que o custo de produção ficou mais caro e induzir a um consumo mais eficiente. No entanto, o aumento das bandeiras tarifárias atinge diretamente a econômica nos indicadores de inflação, sendo sentido rapidamente pela sociedade e pelo Governo, segundo, (Valor Econômico, 2021)

Além disso, foi implementado um programa de bonificação aos clientes de baixa tensão com o objetivo de reduzir o consumo entre $10 \%$ e $20 \%$ ao longo do último quadrimestre de 2021, o que poderá gerar um bônus de até $\mathrm{R} \$ 100$ reais a cada $100 \mathrm{kWh}$ economizados.

Segundo (PSR, 2021), existe uma oportunidade regulatória na elaboração de uma regulação prévia sobre como deveriam ser tratados os eventos em caso de racionamento de energia.

Outro assunto considerado estruturante seria a questão do uso múltiplo da água pelas Usinas hidrelétricas, pois, é um tema de relevantes impactos para economia, meio ambiente e para produção de energia que remete a necessidade de uma avaliação de custos para o país, a partir de uma visão holística.

O Brasil vive um dilema de possuir uma matriz de energia renovável com baixo custo de produção de energia, mas, com uma fatura extremamente elevada, tendo em vista, a distorção produzida pelos encargos, impostos e custos não gerenciáveis (Térmicas e Risco Hidrológico). O impacto das mudanças climáticas pode afetar diretamente o regime de chuvas no país, o que exige uma revisão os conceitos e estratégias para equilibrar uma geração sustentável com uma tarifa justa a ser paga pelos consumidores, em especial, após a Pandemia COVID 19, que enfraqueceu a economia e a malha social, conforme (SALES, 2021).

\section{REFERÊNCIAS}

CALDAS, Pereira Geraldo. Concessões de Serviços Públicos de Energia Elétrica. 2. ed. Curitiba: Juruá, 2011. 
CANAL ENERGIA, Rodrigues, Robson. Medidas contra a crise hídrica vão causar um rombo de R\$ 140 bilhões. 22 de dezembro de 2021.

CHRISTOFARI, Vilson D. O setor de Energia Elétrica: Aspectos Físicos e Regulamentação. 1. ed. São Paulo: ABCE, 2015.

SALES, Claudio; MONTEIRO, Eduardo. A Crise Hídrica: Causas, Respostas e Reflexões. Revista Brasil Energia Online. Acende Brasil, Dezembro, 2021.

DE ARAÚJO, João Lizardo. A questão do investimento no setor elétrico brasileiro: reforma e crise. Nova economia, v. 11, n. 1, 2001.

INSTITUTO ACENDE BRASIL. Concessões do setor elétrico: alternativas de políticas públicas. White paper. $n^{\circ} 5$, nov. 2011.

Kelman, Gerson. Relatório da Comissão de Análise do Sistema Hidrotérmico. Brasília, 2001.

PIRES, José Claudio; PICCININI, Mauricio. Modelos de Regulação Tarifária do Setor Elétrico. 5. ed. Rio de Janeiro:Revista do BNDES, 1998.

PSR Consultoria. Energy Report - Edição No 160 - Vivendo e (Esperamos) Apreendendo com as Crises do Setor Elétrico. Brasília, 2020.

PSR Consultoria. Energy Report - Edição No 173 - Suprimento de Energia e Ponta: Separando o Sinal do Ruído. Brasília, 2021.

SAUER, I. L.; VIEIRA, J. P.; KIRCHNER, C. A. R. O racionamento de energia elétrica decretado em 2001: um estudo sobre as causas e as responsabilidades. São Paulo: IEEUSP, 2001.

TOLMASQUIM, Mauricio T. O Novo Modelo do Setor Elétrico Brasileiro. 2. ed. Brasília: Synergia, 2015. 
REVISTA USP. Dossiê Energia Elétrica. Março, 2015

VALOR ECONOMICO, Mello, João Carlos. Uma Roleta Russa Chamada Chuva. 17 de dezembro de 2021.

Recebido em: 20/01/2022

Aprovado em: 21/02/2022

Publicado em: 25/02/2022 